\title{
Inflammation as a potential link between nonalcoholic fatty liver disease and insulin resistance
}

\author{
Mohamed Asrih and François R Jornayvaz \\ Service of Endocrinology, Diabetes, Hypertension and Nutrition, Geneva University Hospital, \\ Rue Gabrielle-Perret-Gentil 4, 1211 Genève 14, Switzerland
}

Correspondence should be addressed to F R Jornayvaz Email francois.jornayvaz@hcuge.ch

\begin{abstract}
Nonalcoholic fatty liver disease (NAFLD) has become a major health problem in developed countries. It has affected more than $30 \%$ of the general population and is commonly associated with insulin resistance, which is a major risk factor for the development of type 2 diabetes and a central feature of the metabolic syndrome. Furthermore, accumulating evidences reveal that NAFLD as well as insulin resistance is strongly related to inflammation. Cytokines and adipokines play a pivotal role in inflammatory processes. In addition, these inflammatory mediators regulate various functions including metabolic energy balance, inflammation, and immune response. However, their role in modulating ectopic lipids involved in the development of insulin resistance, such as diacylglycerols and ceramides, remains unknown. The aim of this review is first to describe the pathophysiology of insulin resistance in NAFLD. In particular, we discuss the role of ectopic lipid accumulation in the liver. Secondly, we also summarize recent findings emphasizing the role of main inflammatory markers in both NAFLD and insulin resistance and their potential role in modulating hepatic fat content in NAFLD and associated hepatic insulin resistance.
\end{abstract}
Key Words
- liver
- insulin resistance
- inflammatory diseases
- lipid
- obesity

\section{Introduction}

Nonalcoholic fatty liver disease (NAFLD) is a major health problem considered to be the most common chronic liver disorder in the Western countries. NAFLD is estimated to affect at least $30 \%$ of the general population (Ratziu et al. 2010, Younossi et al. 2011). It is histologically characterized by hepatic triglyceride (TG) accumulation of more than $5 \%$, resulting in steatosis and hepatic inflammation (Tarantino et al. 2010). NAFLD includes a complex spectrum of disorders ranging from simple fatty liver to nonalcoholic steatohepatitis (NASH) and cirrhosis (Adams et al. 2005). NAFLD has been first considered to be a benign disease, but it is now being recognized as a leading cause of liver-related mortality and morbidity in the Western countries. This consideration of NAFLD as a benign disease can be explained by the fact that simple actions such as lifestyle interventions, i.e. dietary changes and physical activity, can reverse simple hepatic steatosis. However, when disease-promoting factors such as eating an unhealthy diet persist, simple steatosis progresses to NASH, which is characterized by inflammation and fibrosis, and can then evolve into cirrhosis and to a lesser extent to hepatocellular carcinoma (Gariani et al. 2013). Whether NAFLD should be considered as a progressive disease encompassing different stages, or each stage should be distinguished as a single disease, is still controversial. Importantly, NAFLD is strongly associated

Published by Bioscientifica Ltd. 
with obesity, insulin resistance, hypertension, and dyslipidemia, suggesting that NAFLD might be considered as the liver manifestation of the metabolic syndrome (Marchesini et al. 2001, Adams et al. 2005).

The metabolic syndrome is a leading cause of mortality and morbidity in industrialized countries and is characterized by the combination of multiple disorders including insulin resistance, abdominal obesity, dyslipidemia, increased blood pressure, hypercholesterolemia, and a pro-inflammatory state (Eckel et al. 2005, Alberti et al. 2009). One of the central features of this syndrome is obesity, probably the fastest growing problem in the Western world. Obesity, which is often associated with insulin resistance, represents a chronic low-grade inflammatory state, characterized by elevated circulating levels of cytokines and activation of pro-inflammatory signaling pathways (Shoelson et al. 2006). In contrast, others have revealed controversial data showing that obesity is not necessarily associated with an inflammatory state (Apovian et al. 2008, Stefan et al. 2008). Therefore, it is not surprising that several studies have documented the role of inflammation in the development of insulin resistance. Similarly, others have revealed a link between inflammation and NAFLD. Despite these correlations, it remains unclear whether inflammation could be a common link between insulin resistance and NAFLD. Thus, in this review, we will first update and summarize current knowledge about the cellular mechanisms involved in the development of insulin resistance associated with NAFLD, focusing on the role of ectopic lipid deposition in this process, i.e. deposition of lipids outside of the adipose tissue, such as in the liver or skeletal muscle. As an inflammatory state is frequently associated with NAFLD and insulin resistance, several studies focused on the role of numerous inflammatory mediators in these disorders and have been reviewed elsewhere (Tilg 2010). However, tumor necrosis factor $\alpha$ (TNF $\alpha$ ), interleukin 6 (IL6), IL10, and adiponectin are considered to be the major inflammatory mediators found in NAFLD and insulin resistance and will thus be discussed here in more detail. Therefore, we also aim at updating and discussing recent studies describing how these molecules impair insulin responsiveness and concomitantly contribute to NAFLD.

\section{Update on the molecular mechanisms of insulin resistance in NAFLD}

The molecular etiology of NAFLD involves multiple genetic and nongenetic mechanisms contributing to the final phenotype (Amarapurkar et al. 2007, Das et al. 2010).
However, this pathophysiology is far from being completely elucidated. Besides the genetic susceptibility to develop the disease (Gariani et al. 2013), it appears that promoting factors notably include i) lipid intermediate accumulation, ii) altered expression of pro-inflammatory cytokines, and iii) mitochondrial dysfunction (Day \& James 1998, Diehl et al. 2005, Begriche et al. 2006).

Under physiological conditions, fatty acids (FAs) are transported to various organs including liver and skeletal muscle; thereafter, FAs undergo either $\beta$-oxidation in the mitochondria or are stored as TGs. Hepatic TG storage mainly originates from lipolysis of TGs released from white adipose tissue (Donnelly et al. 2005). The rest of the lipid stores derive from dietary FAs and de novo lipogenesis. Imbalances between these pathways lead to excessive FA flux and accumulation, which not only induces hepatic (and skeletal muscle) insulin resistance but also impairs insulin responsiveness at the level of the whole organism (Svedberg et al. 1991, Wiesenthal et al. 1999, Carpentier et al. 2000, Balent et al. 2002). This altered lipid metabolism is believed to be a central mechanism in the development of insulin resistance. Most of the adverse effects induced by FA accumulation are likely to be mediated by lipid intermediates, notably diacylglycerols (DAGs) and ceramides (Jornayvaz \& Shulman 2012). Lipid intermediates can induce insulin resistance by activating different kinases such as mammalian target of rapamycin (mTOR), inhibitor of $\kappa \mathrm{B}$ kinase (IKK), Jun N-terminal kinase (JNK), and novel protein kinase C (nPKC) that are known to exert negative feedback on proximal insulin signaling (Fig. 1; Petersen \& Shulman 2006, Schenk et al . 2008). Together, this contributes to the insulin-resistant state frequently encountered in patients with NAFLD (Bugianesi et al. 2005a, Kotronen et al. 2008).

Recently, it has been observed that under hyperinsulinemic conditions, hepatocytes present a paradoxical response to insulin stimulation. Indeed, although insulin failed to inhibit FOXO protein, a master regulator of gluconeogenesis, it is still able to promote de novo lipogenesis (Brown \& Goldstein 2008). A potential mechanism to explain this situation is that insulin activates sterol regulatory element-binding protein-1c (SREBP1C), a master regulatory transcription factor in lipid synthesis, through stimulation of the mTOR complex 1, which results in increased lipogenesis (Laplante \& Sabatini 2010, Yecies et al. 2011). Therefore, insulin resistance characterized by a hyperinsulinemic state as observed in patients with NAFLD increases de novo lipogenesis, which further exacerbates hepatic lipid deposition and accelerates the development of the disease.

Published by Bioscientifica Ltd. 


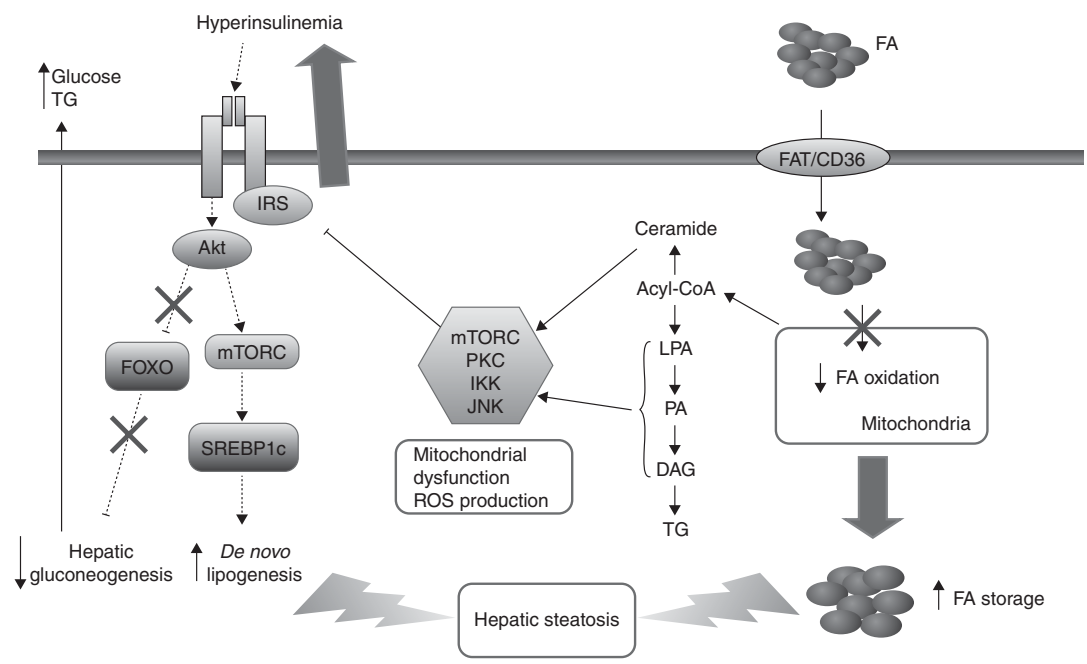

\section{Figure 1}

Schematic representation of cellular pathways involved in the development of nonalcoholic fatty liver disease. Under physiological conditions fatty acids (FA) enter the cell and are either oxidized or stored. When the influx/outflow ratio is altered, FA accumulate, leading to hepatic steatosis, inflammation, altered mitochondrial function and increased lipid intermediates [LPA: lysophosphatidic acids; PA: phosphatidic acid, DAG: diacylglycerol and TG: triglycerides]. In turn, these lipid intermediates activate various kinases [mammalian target of rapamycin (mTOR), inhibitor

However, it is important to emphasize that TG pool derived from de novo lipogenesis only accounts for a minor part of hepatic TG accumulation related to NAFLD (Donnelly et al. 2005).

Because of the major role of FA in the development of NAFLD, several strategies have targeted lipid synthesis to reduce hepatic steatosis (An et al. 2004, Samuel et al. 2004, Savage et al. 2006). Acyl-coenzyme A:DAG acyltransferase (DGAT) is an enzyme involved in the final step in TG synthesis and has therefore been proposed as a potential target to reduce TG accumulation and hepatic steatosis. Indeed, inhibition of DGAT2 expression by antisense oligonucleotides reduced hepatic steatosis and improved insulin sensitivity in diet-induced obese and leptindeficient mice with early stage of NAFLD (Yu et al. 2005, Choi et al. 2007). Surprisingly, DGAT2 inhibition worsened liver injury and fibrosis. This study revealed a protective role for TG accumulation that appears to buffer the harmful effects of FA-induced lipotoxicity (Choi \& Diehl 2008).

As mentioned earlier, FA influx to the liver leads to hepatic steatosis but also induces insulin resistance through the accumulation of toxic lipid intermediates, mostly DAG and ceramides. One hypothesis suggests that increased levels of DAG promote insulin resistance by interfering with the proximal insulin signaling. of kappa-B kinase (IKK), Jun $\mathrm{N}$-terminal kinase (JNK), and novel protein kinase $C(P K C)$ ] that inhibit proximal insulin signaling, mainly through insulin receptor substrate (IRS) inhibition. Increased insulinemia stimulates de novo lipogenesis via activation of sterol regulatory element-binding protein-1C (SREBP1C), hence exacerbating steatosis. In addition, under insulin resistant conditions, insulin fails to inhibit FOXO pathway that mediates gluconeogenesis. Altogether, these intracellular pathways finally promote NAFLD and insulin resistance.

This hypothesis has been confirmed in numerous rodent models of hepatic insulin resistance (Jornayvaz et al. 2010, 2011, 2012, Birkenfeld et al. 2011a,b, Lee et al. 2011, Jurczak et al. 2012, Camporez et al. 2013, Cantley et al. 2013). Surprisingly, an important study by Monetti et al. did not confirm the role of DAG in mediating insulin resistance. These authors generated transgenic mice overexpressing DGAT2 in the liver. A decrease in hepatic DAG content with concomitant improved insulin sensitivity could be expected. However, the authors reported increased hepatic DAG content associated with the development of NAFLD. Owing to the key role of DAG in mediating hepatic insulin resistance and the link between NAFLD and insulin resistance (Jornayvaz \& Shulman 2012), one may expect worsened insulin sensitivity in this animal model. Paradoxically, the authors found a dissociation of hepatic steatosis and insulin resistance in this model (Monetti et al. 2007). In contrast to these results, Jornayvaz et al. (2011) found severe hepatic insulin resistance associated with NAFLD concomitant with DAG accumulation using the same animal model. These controversial findings point to different possibilities to explain the discrepancies between these two studies: i) a difference in the diet? ii) a different genetic background? or iii) different methods used to assess insulin sensitivity? Because the critical difference

Published by Bioscientifica Ltd. 
between these studies was the hyperinsulinemic-euglycemic clamp technique used to assess hepatic and peripheral insulin response, Jornayvaz \& Shulman (2012) suggested this as a possible explanation to the discrepancy. Although these findings remain a question of debate, this emphasizes the need for standard operating procedures when performing the gold standard hyperinsulinemic-euglycemic clamp technique in mice (Ayala et al. 2010).

Also, ceramides appear to play a role in the development of insulin resistance and have recently drawn the attention of the scientific community. Ceramides are a family of lipids composed of a sphingosine and FA group. Their production was believed to be mainly dependent on the availability of palmitate, which is the initial substrate. However, recent studies reported that tissue ceramide synthesis is modulated by several factors including hormones, inflammatory molecules, and saturated FAs. Together, these factors can lead to ceramide accumulation and further insulin resistance (Bikman \& Summers 2011). The involved mechanisms are far from being completely eluded; nevertheless, it is proposed that ceramides interfere with insulin signaling through activation of the PKC $\zeta$ isoform, which in turn inhibits Akt and leads to increased levels of protein phosphatase $2 \mathrm{~A}$, which finally results in mitochondrial dysfunction and endoplasmic reticulum stress (Gariani et al. 2013). In summary, accumulation of ceramides alters a large number of intracellular signaling events, leading to metabolic dysfunctions. Thus, modulating ceramide synthesis could be considered as a potential therapeutic approach to prevent the development of insulin resistance.

Whether TG storage in the liver is protective or not in NAFLD remains an open question. Therefore, further studies are required to clarify this issue. Nonetheless, it appears that accumulation of certain lipid intermediates, such as DAG and ceramides, plays a central role in the development of NAFLD-associated hepatic insulin resistance. As most of fat accumulation in NAFLD is due to the release of FA from white adipose tissue, this highlights the importance of a potential cross talk between white adipose tissue and liver and suggests that white adipose tissue plays an important role in the development of NAFLD and will therefore be discussed in the next section.

\section{Role of white adipose tissue in insulin resistance}

Insulin resistance is described as the inability of insulin to stimulate glucose uptake (Bugianesi et al. 2005b). It is now recognized that the molecular etiology of insulin resistance involves multiple genetic and nongenetic mechanisms contributing to the final phenotype. Growing bodies of evidence suggest a role for white adipose tissue in the development of insulin resistance. It is proposed that insulin resistance is associated with hyperlipidemia, which is due to highly abnormal breakdown of the TG pool.

As discussed earlier, the release of substantial quantities of FA from the white adipose tissue gets accumulated as lipid droplets within different organs including the liver, the myocardium, and the skeletal muscle (Unger 2001). This pathological accumulation of FA has been associated with lipotoxicity and insulin resistance (Unger 2002). It appears that insulin resistance is not a direct result of exposure to FA but rather to their lipid-derived metabolites. These metabolites promote the activation of numerous kinases, including the nPKC isoforms ( $\varepsilon$ in the liver and $\theta$ in the skeletal muscle), MAPK, ERKs, and c-Jun, S6K, and IKK $\beta$ (Kim et al. 2001, Boden \& Shulman 2002, Park et al. 2008). In turn, these kinases phosphorylate the insulin receptor substrate (IRS), which has either positive or negative effects on the insulin pathway (Tanti \& Jager 2009). In line with these results, several studies investigating the mechanisms of insulin resistance have reported that any defects in the IRS gene contribute to insulin resistance, therefore identifying IRS as a major target in this disorder (Bandyopadhyay et al. 2005, Hoehn et al. 2008). Nevertheless, there are several limitations to this model: first, it does not take into account the process of translocation of the glucose transporters to the plasma membrane, which is the ultimate and main event of insulin-induced glucose uptake, notably in skeletal muscle. Secondly, defects in the activation of insulin-targeted substrates are not always associated with insulin resistance (Nadler et al. 2001). Thirdly, it has been shown that partial inhibition of IRS does not substantially affect metabolism (Nadler et al. 2001, Cleasby et al. 2007, Hoehn et al. 2008). Therefore, defects in IRS could be considered as another factor contributing to the development of insulin resistance but not as the main element causing insulin resistance.

In addition, increased FA oxidation has been shown to enhance reactive oxygen species production and oxidative stress. It is believed that oxidative stress impairs the trafficking of the insulin signaling components, hence leading to insulin resistance (Cleasby et al. 2007). Furthermore, it is also argued that the ERK1/2, which belongs to the family of MAPKs, plays a pivotal role in metabolic regulation. Indeed, it has been shown that skeletal muscle samples from insulin-resistant patients have increased ERK activation compared with healthy

Published by Bioscientifica Ltd. 
patients (Bandyopadhyay et al. 2005). In line with these findings, others found that mice deficient in the signaling adapter p62, an ERK inhibitor protein, develop obesity and insulin resistance associated with enhanced basal level of ERK activity (Rodriguez et al. 2006).

Moreover, there is also an evidence indicating that white adipose tissue not only stores excessive FAs but also synthesizes and secretes a cohort of active molecules (Boden \& Shulman 2002). In fact, it has now become evident that white adipose tissue is capable of secreting hormones as well as cytokines. Indeed, Hotamisligil et al. (1993) have shown that adipocytes have immune cell-like properties such as production and secretion of proinflammatory cytokines. Others indicated that hormones and cytokines secreted by adipocytes are capable of modulating inflammation as well as glucose and lipid metabolism homeostasis (Wellen \& Hotamisligil 2005).

In summary, white adipose tissue not only releases FA that can accumulate in peripheral organs such as the liver, leading to NAFLD and hepatic insulin resistance, but also secretes inflammatory molecules, cytokines, that can further modulate insulin resistance. The role of main cytokines in NAFLD and hepatic insulin resistance will be discussed in the next section.

\section{Role of cytokines in NAFLD and insulin resistance}

Chronic excessive caloric intake along with sedentary lifestyle not only promotes insulin resistance development but also leads to obesity. As mentioned earlier, obesity is now recognized as a chronic inflammatory disease that contributes to the development of various pathologies including cardiovascular diseases, type 2 diabetes, and NAFLD (Colicchio et al. 2005, Flegal et al. 2007, Freedman 2011, Tarantino \& Caputi 2011). Whether obesity precedes insulin resistance or vice versa is however still a matter of debate. Weight loss is particularly important in improving NAFLD but also glucose metabolism and cardiovascular risk (Musso et al. 2012). Notably, in patients with type 2 diabetes and NAFLD, Petersen et al. have shown that moderate weight reduction (about $8 \mathrm{~kg}$ ) was sufficient to improve NAFLD and reverse hepatic insulin resistance (Petersen et al. 2005).

Importantly, inflammation is one of the major risk factors associated with obesity and is related to white adipose tissue dysfunction, i.e. functions other than TG storage. Indeed, white adipose tissue was first considered as a passive non-secretory, inert tissue whose exclusive function is to store TGs in excess and to release them back during caloric restriction in order to meet the energy body needs. However, recent findings unveiled this concept and described white adipose tissue as an active endocrine organ capable of synthesizing and secreting a multitude of hormones, cytokines, chemokines, and enzymes collectively known as adipokines (Halberg et al. 2008, Lumeng \& Saltiel 2011). The adipokine profile secretion is a dynamic process depending on fat mass status. In fact, pro-inflammatory cytokine expression (e.g. TNF $\alpha$ and IL6) is increased, whereas anti-inflammatory protein expression (e.g. adiponectin and IL10) is decreased during weight gain and therefore fat mass expansion (Hotamisligil et al. 1995, Yang et al. 2001, Jung et al. 2008). Moreover, altered adipokine pattern associated with obesity is also observed in patients with NAFLD (Tilg \& Diehl 2000) as well as in patients developing insulin resistance (Odegaard \& Chawla 2013). As there is a close link between NAFLD, insulin resistance, and inflammation, it is not surprising that extensive efforts have been taken to understand the role of adipokines in the development of NAFLD and insulin resistance. Thus, in the following section, we will provide an overview of the pathophysiological role of major adipokines (TNF $\alpha$, IL6, IL10, and adiponectin) in NAFLD and insulin resistance (Table 1).

\section{Tumor necrosis factor $\alpha$}

Almost two decades ago, TNF $\alpha$ was identified as the first inflammatory molecule linking obesity with insulin resistance (Lang et al. 1992). TNF $\alpha$ is produced by a variety of cells including adipocytes. Nevertheless, under physiological conditions, TNF $\alpha$ is expressed at low levels. In contrast, $\mathrm{TNF} \alpha$ is overexpressed in white adipose tissue of obese rodent models ( $\mathrm{Xu}$ et al. 2002). Furthermore, it was observed that obese individuals with insulin resistance exhibit a higher adipose TNF $\alpha$ mRNA level relative to lean patients (Arner 2003), suggesting that TNF $\alpha$ may play a role in the pathophysiology of insulin resistance. Therefore, several approaches targeting TNF $\alpha$ were developed to treat insulin resistance. For instance, neutralization of TNF $\alpha$ with chimeric antibody increased insulin sensitivity (Hotamisligil et al. 1993). Consistently, it was shown that TNF $\alpha$ or $\mathrm{TNF} \alpha$ receptor knockout obese mice exhibit improved insulin sensitivity compared with wild-type obese mice (Uysal et al. 1997). In contrast to these studies using animal models, injection of an engineered antibody against TNF $\alpha$ in type 2 diabetic patients had no effect on insulin sensitivity (Ofei et al. 1996), thus suggesting that insulin resistance is a multifactorial disorder involving some factors that are human specific. Indeed, others evaluating

Published by Bioscientifica Ltd 
Table 1 Summary of the most relevant cytokines involved in NAFLD and insulin resistance and their roles in these diseases

\begin{tabular}{ll}
\hline Cytokines & References \\
\cline { 1 - 2 } TNF $\alpha$ & Xu et al. (2002) \\
& Arner (2003) \\
& Hotamisligil (2003) \\
& Uysal et al. (1997) \\
& Meyer \& de Groot (2003) \\
& Tilg \& Diehl (2000) \\
& Lesmana et al. (2009) \\
& Zhou et al. (2010) \\
& Bastard et al. (2002) \\
IL6 & El-Assal et al. (2004) \\
& Wallenius et al. (2002) \\
& Wieckowska et al. (2008) \\
& Yamaguchi et al. (2010) \\
& Marra \& Bertolani (2009) \\
& Cintra et al. (2008) \\
IL10 & Arita et al. (1999) and Hotta et al. (2000) \\
& Kumada et al. (2004) and Wolf et al. (2004) \\
& Hui et al. (2004) \\
Adiponectin &
\end{tabular}

\section{Findings and role in insulin resistance and NAFLD}

TNF $\alpha$ is present in white adipose tissue and its production is significantly increased in different rodent obesity models TNF $\alpha$ level correlates with insulin resistance

Blocking TNF $\alpha$ with an antibody increases insulin sensitivity Mice lacking TNF $\alpha$ function are protected against obesity-induced insulin resistance

TNF $\alpha$ induces cytotoxicity through regulation of ceramide synthesis Increased TNF $\alpha$ level in NAFLD patients

Correlation between TNF $\alpha$ and degree of liver fibrosis in NAFLD subjects High prevalence of certain TNF $\alpha$ polymorphisms in patients with NAFLD Pharmacological inhibition of TNF $\alpha$ reduces aminotransferase levels in patients with NAFLD

IL6 produced by white adipose tissue contributes to insulin resistance observed in obese humans

IL6 protects against ethanol-induced liver injury

IL6-deficient mice develop mature onset obesity and associated insulin resistance

Hepatic IL6 expression correlates with the severity of NAFLD

Blocking IL6 prevents liver damage and enhances liver steatosis IL10 ameliorates hepatocytes damage

IL10 prevents liver steatosis in mice models of liver disease, although it does not protect against insulin resistance

Positive correlation between adiponectin levels and insulin resistance Adiponectin induces anti-inflammatory effects through IL10 expression Low levels of adiponectin in patients presenting hepatic steatosis the effect of salsalate, an anti-inflammatory drug, on insulin resistance revealed that several markers of glycemia were lowered in treated subjects compared with controls (Goldfine et al. 2010). However, this study presents some limitations. Notably, the levels of relevant markers of inflammation related to insulin resistance (such as IL6 and $\mathrm{TNF} \alpha$ ) were not reported. As insulin resistance can be considered as a chronic inflammatory disease, it would have been worthy to pursue the study more than 14 weeks. Taken together, these results indicate that treatments using anti-inflammatory molecules to prevent insulin resistance are still debatable and need further research.

Nevertheless, the mechanisms involved in TNF $\alpha$ induced insulin resistance are not fully understood, although it is believed that TNF $\alpha$ inhibits insulin signaling mainly by affecting the IRS protein (Hotamisligil 2003). First, TNF $\alpha$ binds to a classical cytokine receptor and activates various MAPKs including JNK and p38 MAPK in addition to PKC and IKK activation. These proteins in turn phosphorylate IRS and the insulin receptor, leading to inhibition of insulin signaling (Weickert \& Pfeiffer 2006). Secondly, TNF $\alpha$ can activate de novo ceramide synthesis, likely via induction of sphingomyelinase that converts sphingomyelin to ceramides (Chatterjee 1993, Meyer \& de Groot 2003). In turn, ceramides, concomitantly with DAG, activate different kinases interacting with IRS phosphorylation, finally inhibiting insulin signaling (Griffin et al. 1999, Itani et al. 2002, Summers 2006).

In addition to its role in the development of insulin resistance, TNF $\alpha$ is believed to be a key mediator in NAFLD (Tilg \& Diehl 2000). In fact, TNF $\alpha$ plasma levels have been shown to positively correlate with the degree of liver fibrosis when assessed by the ultrasound-guided liver biopsy method in patients with advanced stages of NAFLD (Lesmana et al. 2009). In line with these results, increased levels of TNF $\alpha$ were observed in patients with steatohepatitis compared with healthy subjects (Hui et al. 2004). Moreover, it has been established that certain TNF $\propto$ polymorphisms increase the susceptibility to NAFLD (Zhou et al. 2010). Taken together, these results indicate that TNF $\alpha$ may be an adapted therapeutic target to treat NAFLD. In fact, pharmacological inhibition of TNF $\alpha$ with pentoxifylline in combination with diet and exercise significantly reduced aminotransferases levels in patients with NASH when compared with controls (Lee et al. 2008), suggesting that this treatment might prevent the development of NAFLD. However, this approach is very optimistic as NAFLD may develop without any changes in the circulating levels of TNF $\alpha$ (Lucero et al. 2011). Therefore, several controversies remain to be clarified regarding the pathological role of $\mathrm{TNF} \alpha$ in NAFLD.

Published by Bioscientifica Ltd. 
In summary, metabolic alterations leading to lipid accumulation promotes local TNF $\alpha$ production (e.g. liver) and kinase activation. In turn, TNF $\alpha$ activates various inflammatory signaling pathways that inhibit insulin signaling, resulting in insulin resistance, which represents an important risk factor for the development of NAFLD. Therefore, TNF $\alpha$ could be proposed as a common mediator of insulin resistance and NAFLD.

\section{Interleukin 6}

IL6 is a pleiotropic cytokine involved in the immune response and produced by various cell types including fibroblasts, endothelial cells, monocytes, and adipocytes (Gwechenberger et al. 1999). IL6 content in the adipose tissue correlates with insulin resistance assessed by a hyperinsulinemic-euglycemic clamp in obese subjects with and without diabetes (Bastard et al. 2002). Although the exact mechanism has not been clearly elucidated, it is suggested that IL6 binds to its receptor and thereby recruits signaling transducer proteins, such as the JAKs/STATs. Thereafter, JAK activation induces STAT phosphorylation, dimerization, and translocation to the nucleus, leading to transcription of several genes, such as the suppressor of cytokine signaling (SOCS), which is known to alter proximal insulin signaling through inhibition of IRS phosphorylation (Ueki et al. 2004). Therefore, these studies reveal that high levels of IL6 could contribute to insulin resistance.

As IL6 induces a plethora of effects including insulin resistance and regulation of inflammation, known to be risk factors for NAFLD, it has been proposed as a potential mediator leading to NAFLD (Kishimoto 2010). However, until now, the mechanisms driving IL6-induced NAFLD remain unclear. Preliminary studies found that IL6 plays a protective role in liver fibrosis by promoting hepatocyte proliferation and by protecting against oxidative stress and mitochondrial dysfunction (Cressman et al. 1996, El-Assal et al. 2004). On the other hand, mice lacking IL6 develop insulin resistance and mature onset obesity (Wallenius et al. 2002), which are major risk factors for the development of NAFLD. Furthermore, Wieckowska et al. (2008) showed a positive correlation between IL6 hepatic expression and the severity of NAFLD. Thus, although IL6 improves liver injury, it could not be excluded that it may participate to the development of NAFLD. For instance, blocking IL6 in mice presenting a diet-induced NASH prevents liver injury but concomitantly enhances steatosis (Yamaguchi et al. 2010). Altogether, these studies provide controversial results for the role of IL6 in NAFLD and insulin resistance that needs to be further investigated.

\section{Interleukin 10}

In contrast to TNF $\alpha$ or IL6, IL10 is an anti-inflammatory cytokine that ameliorates hepatocellular damage (Marra \& Bertolani 2009). This cytokine is mainly produced by the liver, which releases it massively after ectopic transplantation (Le Moine et al. 1994, Alfrey et al. 1995).

Nonetheless, controversies remain on the role of IL10 in high-fat diet-induced liver steatosis and insulin resistance. It was reported that endogenous IL10 does not protect against insulin resistance, although it prevents liver steatosis in mouse models of liver disease (den Boer et al. 2006). In this study, glucose and lipid metabolism was analyzed in $I l 10^{-1-}$ mice and wild-type mice fed a high-fat diet for 6 weeks to induce steatosis and insulin resistance. After 6 weeks on the high-fat diet, no differences in body weight, basal metabolism, or plasma levels of glucose, TGs, or cholesterol were observed between the two groups. However, hepatic TG content was increased by $\sim 55 \%$ in $I l 10^{-/-}$mice. In addition, no differences were observed in whole-body or hepatic insulin sensitivity between both groups. Therefore, the authors concluded that basal IL10 production protects against hepatic steatosis but does not improve hepatic or whole-body insulin sensitivity during high-fat feeding. Unfortunately, apart from hepatic TG content, which is usually considered inert, lipid intermediates involved in insulin resistance such as DAG and ceramides were not measured. Moreover, in another mouse model of NAFLD, IL10 inhibition using a neutralizing antibody or antisense oligonucleotides aggravated insulin resistance by increasing TNF $\alpha$ and IL6 expression in liver (Cintra et al. 2008). Again, the effect of IL10 inhibition on hepatic lipid content, particularly DAG and ceramides, was not assessed.

In summary, current evidence suggests a beneficial role of IL10 in hepatic steatosis, although its effects on insulin resistance remain controversial. Therefore, more studies are needed to assess the potential role of IL10 in decreasing hepatic lipid content by measuring not only hepatic TG content but also lipid intermediates involved in the development of insulin resistance such as DAG and ceramides.

\section{Adiponectin}

Adiponectin is an anti-inflammatory mediator secreted mainly by the white adipose tissue. Similar to other

Published by Bioscientifica Ltd 
cytokines, its exact function remains uncertain, although it appears to potentially stimulate ceramide catabolism (Holland et al. 2011). This in turn protects against apoptosis and may prevent the development of insulin resistance. Supporting this hypothesis, several research groups have found a positive correlation between adiponectin levels and insulin resistance as well as fat mass (Arita et al. 1999, Hotta et al. 2000).

Several reports revealed that adiponectin promotes its anti-inflammatory effects through the induction of IL10 (Kumada et al. 2004, Wolf et al. 2004). Furthermore, adiponectin has been shown to inhibit the IKK signaling inflammatory pathway. Altogether, these results suggest that in addition to its role on insulin resistance, adiponectin may be involved in liver diseases associated with insulin resistance and inflammation such as NAFLD. Indeed, Hui et al. (2004) found lower adiponectin levels in patients developing steatosis compared with control subjects. However, patients with cirrhotic liver disease (i.e. in the late stage of NAFLD) present increased adiponectin levels (Moschen et al. 2012).

Although these results need confirmation and further research, it appears that adiponectin could be a potential therapeutic target to prevent the development of NAFLD and its progression to cirrhosis. However, again, adiponectin levels should be correlated with different hepatic lipid intermediates involved in the development of insulin resistance to better delineate its role as a potential therapeutic target in NAFLD and hepatic insulin resistance.

\section{Interaction between adipokines}

In the previous sections, we deliberately decided to present major adipokines, but it is clear that the interaction and cross talk of all these molecules, including less-studied adipokines, should be kept in mind, notably when evaluating these molecules in vivo. For instance, it has been shown that adiponectin plasma levels are inversely associated with IL6 and TNF $\alpha$ (Bruun et al. 2003, Engeli et al. 2003, Kern et al. 2003). Together, these results suggest that adiponectin may be inhibited by endogenous cytokines (such as IL6) and this knowledge could be of major importance in targeting these molecules in order to prevent insulin resistance.

\section{Conclusions}

White adipose tissue is the main source of ectopic fat accumulation, notably in the liver, leading to NAFLD. NAFLD almost always results in insulin resistance through the accumulation of toxic lipid intermediates such as DAGs and ceramides, which lead to inhibition of the insulin signaling cascade. This ectopic fat accumulation in the liver and the subsequent hepatic insulin resistance result in inflammation, which is secondary to cytokines release, either locally by the liver or systematically by the white adipose tissue. These cytokines may either exacerbate NAFLD and insulin resistance, such as TNF $\alpha$ or IL6 or try to compensate the situation, such as IL10 and adiponectin. However, their exact role in NAFLD and hepatic insulin resistance remains to be determined. Notably, modulation of lipid intermediates associated with insulin resistance such as DAGs and ceramides by these inflammatory mediators is unknown and warrants further research. In conclusion, understanding the role of cytokines in the modulation of hepatic fat content might provide new therapeutic targets for conditions associated with hepatic insulin resistance, such as NAFLD, obesity, and type 2 diabetes.

\section{Declaration of interest}

The authors declare that there is no conflict of interest that could be perceived as prejudicing the impartiality of the review reported.

\section{Funding}

This work was supported by the Hjelt Foundation, the Olga Mayenfisch Foundation, the Fondation De Reuter and the Fondation Endocrinologie.

\section{References}

Adams LA, Lymp JF, St Sauver J, Sanderson SO, Lindor KD, Feldstein A \& Angulo P 2005 The natural history of nonalcoholic fatty liver disease: a population-based cohort study. Gastroenterology 129 113-121. (doi:10.1053/j.gastro.2005.04.014)

Alberti KG, Eckel RH, Grundy SM, Zimmet PZ, Cleeman JI, Donato KA, Fruchart JC, James WP, Loria CM, Smith SC Jr et al. 2009 Harmonizing the metabolic syndrome: a joint interim statement of the International Diabetes Federation Task Force on Epidemiology and Prevention; National Heart, Lung, and Blood Institute; American Heart Association; World Heart Federation; International Atherosclerosis Society; and International Association for the Study of Obesity. Circulation 120 1640-1645. (doi:10.1161/CIRCULATIONAHA.109.192644)

Alfrey EJ, Most D, Wang X, Lee LK, Holm B, Krieger NR, Sibley RK, Huie P \& Dafoe DC 1995 Interferon- $\gamma$ and interleukin-10 messenger RNA are up-regulated after orthotopic liver transplantation in tolerant rats: evidence for cytokine-mediated immune dysregulation. Surgery 118 399-404 (discussion 404-405). (doi:10.1016/S0039-6060(05)80351-4) Amarapurkar DN, Hashimoto E, Lesmana LA, Sollano JD, Chen PJ, Goh KL \& Asia-Pacific Working Party on N 2007 How common is nonalcoholic fatty liver disease in the Asia-Pacific region and are there local differences? Journal of Gastroenterology and Hepatology 22 788-793. (doi:10.1111/j.1440-1746.2007.05042.x)

An J, Muoio DM, Shiota M, Fujimoto Y, Cline GW, Shulman GI, Koves TR, Stevens R, Millington D \& Newgard CB 2004 Hepatic expression of 
malonyl-CoA decarboxylase reverses muscle, liver and whole-animal insulin resistance. Nature Medicine 10 268-274. (doi:10.1038/nm995)

Apovian CM, Bigornia S, Mott M, Meyers MR, Ulloor J, Gagua M, McDonnell M, Hess D, Joseph L \& Gokce N 2008 Adipose macrophage infiltration is associated with insulin resistance and vascular endothelial dysfunction in obese subjects. Arteriosclerosis, Thrombosis, and Vascular Biology 28 1654-1659. (doi:10.1161/ATVBAHA.108.170316)

Arita Y, Kihara S, Ouchi N, Takahashi M, Maeda K, Miyagawa J, Hotta K, Shimomura I, Nakamura T, Miyaoka K et al. 1999 Paradoxical decrease of an adipose-specific protein, adiponectin, in obesity. Biochemical and Biophysical Research Communications 257 79-83. (doi:10.1006/bbrc. 1999.0255)

Arner P 2003 The adipocyte in insulin resistance: key molecules and the impact of the thiazolidinediones. Trends in Endocrinology and Metabolism 14 137-145. (doi:10.1016/S1043-2760(03)00024-9)

Ayala JE, Samuel VT, Morton GJ, Obici S, Croniger CM, Shulman GI, Wasserman DH, McGuinness OP \& Consortium NIHMMPC 2010 Standard operating procedures for describing and performing metabolic tests of glucose homeostasis in mice. Disease Models \& Mechanisms 3 525-534. (doi:10.1242/dmm.006239)

Balent B, Goswami G, Goodloe G, Rogatsky E, Rauta O, Nezami R, Mints L, Angeletti RH \& Stein DT 2002 Acute elevation of NEFA causes hyperinsulinemia without effect on insulin secretion rate in healthy human subjects. Annals of the New York Academy of Sciences 967 535-543. (doi:10.1111/j.1749-6632.2002.tb04313.x)

Bandyopadhyay GK, Yu JG, Ofrecio J \& Olefsky JM 2005 Increased p85/55/50 expression and decreased phosphotidylinositol 3-kinase activity in insulin-resistant human skeletal muscle. Diabetes 54 2351-2359. (doi:10.2337/diabetes.54.8.2351)

Bastard JP, Maachi M, Van Nhieu JT, Jardel C, Bruckert E, Grimaldi A, Robert JJ, Capeau J \& Hainque B 2002 Adipose tissue IL-6 content correlates with resistance to insulin activation of glucose uptake both in vivo and in vitro. Journal of Clinical Endocrinology and Metabolism $\mathbf{8 7}$ 2084-2089. (doi:10.1210/jc.87.5.2084)

Begriche K, Igoudjil A, Pessayre D \& Fromenty B 2006 Mitochondrial dysfunction in NASH: causes, consequences and possible means to prevent it. Mitochondrion 6 1-28. (doi:10.1016/j.mito.2005.10.004)

Bikman BT \& Summers SA 2011 Ceramides as modulators of cellular and whole-body metabolism. Journal of Clinical Investigation $\mathbf{1 2 1}$ 4222-4230. (doi:10.1172/JCI57144)

Birkenfeld AL, Lee HY, Guebre-Egziabher F, Alves TC, Jurczak MJ, Jornayvaz FR, Zhang D, Hsiao JJ, Martin-Montalvo A, Fischer-Rosinsky A et al. $2011 a$ Deletion of the mammalian INDY homolog mimics aspects of dietary restriction and protects against adiposity and insulin resistance in mice. Cell Metabolism 14 184-195. (doi:10.1016/j.cmet. 2011.06.009)

Birkenfeld AL, Lee HY, Majumdar S, Jurczak MJ, Camporez JP, Jornayvaz FR, Frederick DW, Guigni B, Kahn M, Zhang D et al. $2011 b$ Influence of the hepatic eukaryotic initiation factor $2 \alpha$ (eIF $2 \alpha$ ) endoplasmic reticulum (ER) stress response pathway on insulin-mediated ER stress and hepatic and peripheral glucose metabolism. Journal of Biological Chemistry $\mathbf{2 8 6}$ 36163-36170. (doi:10.1074/jbc.M111.228817)

Boden G \& Shulman GI 2002 Free fatty acids in obesity and type 2 diabetes: defining their role in the development of insulin resistance and $\beta$-cell dysfunction. European Journal of Clinical Investigation 32(Suppl 3) 14-23. (doi:10.1046/j.1365-2362.32.s3.3.x)

den Boer MA, Voshol PJ, Schroder-van der Elst JP, Korsheninnikova E, Ouwens DM, Kuipers F, Havekes LM \& Romijn JA 2006 Endogenous interleukin-10 protects against hepatic steatosis but does not improve insulin sensitivity during high-fat feeding in mice. Endocrinology 147 4553-4558. (doi:10.1210/en.2006-0417)

Brown MS \& Goldstein JL 2008 Selective versus total insulin resistance: a pathogenic paradox. Cell Metabolism 7 95-96. (doi:10.1016/j.cmet. 2007.12.009)

Bruun JM, Lihn AS, Verdich C, Pedersen SB, Toubro S, Astrup A \& Richelsen B 2003 Regulation of adiponectin by adipose tissue-derived cytokines: in vivo and in vitro investigations in humans. American Journal of Physiology. Endocrinology and Metabolism 285 E527-E533.

Bugianesi E, Gastaldelli A, Vanni E, Gambino R, Cassader M, Baldi S, Ponti V, Pagano G, Ferrannini E \& Rizzetto M 2005a Insulin resistance in non-diabetic patients with non-alcoholic fatty liver disease: sites and mechanisms. Diabetologia 48 634-642. (doi:10.1007/ s00125-005-1682-x)

Bugianesi E, McCullough AJ \& Marchesini G $2005 b$ Insulin resistance: a metabolic pathway to chronic liver disease. Hepatology 42 987-1000. (doi:10.1002/hep.20920)

Camporez JP, Jornayvaz FR, Lee HY, Kanda S, Guigni BA, Kahn M, Samuel VT, Carvalho CR, Petersen KF, Jurczak MJ et al. 2013 Cellular mechanism by which estradiol protects female ovariectomized mice from high-fat diet-induced hepatic and muscle insulin resistance. Endocrinology 154 1021-1028. (doi:10.1210/en.2012-1989)

Cantley JL, Yoshimura T, Camporez JP, Zhang D, Jornayvaz FR, Kumashiro N, Guebre-Egziabher F, Jurczak MJ, Kahn M, Guigni BA et al. 2013 CGI-58 knockdown sequesters diacylglycerols in lipid droplets/ER-preventing diacylglycerol-mediated hepatic insulin resistance. PNAS 110 1869-1874. (doi:10.1073/pnas.1219456110)

Carpentier A, Mittelman SD, Bergman RN, Giacca A \& Lewis GF 2000 Prolonged elevation of plasma free fatty acids impairs pancreatic $\beta$-cell function in obese nondiabetic humans but not in individuals with type 2 diabetes. Diabetes 49 399-408. (doi:10.2337/diabetes.49.3.399)

Chatterjee S 1993 Neutral sphingomyelinase. Advances in Lipid Research 26 25-48.

Choi SS \& Diehl AM 2008 Hepatic triglyceride synthesis and nonalcoholic fatty liver disease. Current Opinion in Lipidology 19 295-300. (doi:10.1097/MOL.0b013e3282ff5e55)

Choi CS, Savage DB, Kulkarni A, Yu XX, Liu ZX, Morino K, Kim S, Distefano A, Samuel VT, Neschen S et al. 2007 Suppression of diacylglycerol acyltransferase-2 (DGAT2), but not DGAT1, with antisense oligonucleotides reverses diet-induced hepatic steatosis and insulin resistance. Journal of Biological Chemistry 282 22678-22688. (doi:10.1074/jbc.M704213200)

Cintra DE, Pauli JR, Araujo EP, Moraes JC, de Souza CT, Milanski M, Morari J, Gambero A, Saad MJ \& Velloso LA 2008 Interleukin-10 is a protective factor against diet-induced insulin resistance in liver. Journal of Hepatology 48 628-637. (doi:10.1016/j.jhep.2007.12.017)

Cleasby ME, Reinten TA, Cooney GJ, James DE \& Kraegen EW 2007 Functional studies of Akt isoform specificity in skeletal muscle in vivo; maintained insulin sensitivity despite reduced insulin receptor substrate-1 expression. Molecular Endocrinology 21 215-228. (doi:10.1210/me.2006-0154)

Colicchio P, Tarantino G, del Genio F, Sorrentino P, Saldalamacchia G, Finelli C, Conca P, Contaldo F \& Pasanisi F 2005 Non-alcoholic fatty liver disease in young adult severely obese non-diabetic patients in South Italy. Annals of Nutrition \& Metabolism 49 289-295. (doi:10.1159/ 000087295)

Cressman DE, Greenbaum LE, DeAngelis RA, Ciliberto G, Furth EE, Poli V \& Taub R 1996 Liver failure and defective hepatocyte regeneration in interleukin-6-deficient mice. Science 274 1379-1383. (doi:10.1126/ science.274.5291.1379)

Das K, Das K, Mukherjee PS, Ghosh A, Ghosh S, Mridha AR, Dhibar T, Bhattacharya B, Bhattacharya D, Manna B et al. 2010 Nonobese population in a developing country has a high prevalence of nonalcoholic fatty liver and significant liver disease. Hepatology $\mathbf{5 1}$ 1593-1602. (doi:10.1002/hep.23567)

Day CP \& James OF 1998 Steatohepatitis: a tale of two "hits"? Gastroenterology 114 842-845. (doi:10.1016/S0016-5085(98)70599-2)

Diehl AM, Li ZP, Lin HZ \& Yang SQ 2005 Cytokines and the pathogenesis of non-alcoholic steatohepatitis. Gut 54 303-306. (doi:10.1136/gut.2003. 024935)

Donnelly KL, Smith CI, Schwarzenberg SJ, Jessurun J, Boldt MD \& Parks EJ 2005 Sources of fatty acids stored in liver and secreted via lipoproteins 
in patients with nonalcoholic fatty liver disease. Journal of Clinical Investigation 115 1343-1351. (doi:10.1172/JCI23621)

Eckel RH, Grundy SM \& Zimmet PZ 2005 The metabolic syndrome. Lancet 365 1415-1428. (doi:10.1016/S0140-6736(05)66378-7)

El-Assal O, Hong F, Kim WH, Radaeva S \& Gao B 2004 IL-6-deficient mice are susceptible to ethanol-induced hepatic steatosis: IL-6 protects against ethanol-induced oxidative stress and mitochondrial permeability transition in the liver. Cellular \& Molecular Immunology $1205-211$.

Engeli S, Feldpausch M, Gorzelniak K, Hartwig F, Heintze U, Janke J, Mohlig M, Pfeiffer AF, Luft FC \& Sharma AM 2003 Association between adiponectin and mediators of inflammation in obese women. Diabetes 52 942-947. (doi:10.2337/diabetes.52.4.942)

Flegal KM, Graubard BI, Williamson DF \& Gail MH 2007 Cause-specific excess deaths associated with underweight, overweight, and obesity. Journal of the American Medical Association 298 2028-2037. (doi:10.1001/jama.298.17.2028)

Freedman DS 2011 Obesity - United States, 1988-2008. MMWR Surveillance Summaries 60(Suppl) 73-77.

Gariani K, Philippe J \& Jornayvaz FR 2013 Non-alcoholic fatty liver disease and insulin resistance: from bench to bedside. Diabetes \& Metabolism 39 16-26. (doi:10.1016/j.diabet.2012.11.002)

Goldfine AB, Fonseca V, Jablonski KA, Pyle L, Staten MA, Shoelson SE et al. 2010 The effects of salsalate on glycemic control in patients with type 2 diabetes: a randomized trial. Annals of internal medicine 152(6) 346-357.

Griffin ME, Marcucci MJ, Cline GW, Bell K, Barucci N, Lee D, Goodyear LJ, Kraegen EW, White MF \& Shulman GI 1999 Free fatty acid-induced insulin resistance is associated with activation of protein kinase $\mathrm{C}$ theta and alterations in the insulin signaling cascade. Diabetes 48 1270-1274. (doi:10.2337/diabetes.48.6.1270)

Gwechenberger M, Mendoza LH, Youker KA, Frangogiannis NG, Smith CW, Michael LH \& Entman ML 1999 Cardiac myocytes produce interleukin-6 in culture and in viable border zone of reperfused infarctions. Circulation 99 546-551. (doi:10.1161/01.CIR.99.4.546)

Halberg N, Wernstedt-Asterholm I \& Scherer PE 2008 The adipocyte as an endocrine cell. Endocrinology and Metabolism Clinics of North America 37 753-768 (x-xi). (doi:10.1016/j.ecl.2008.07.002)

Hoehn KL, Hohnen-Behrens C, Cederberg A, Wu LE, Turner N, Yuasa T, Ebina Y \& James DE 2008 IRS1-independent defects define major nodes of insulin resistance. Cell Metabolism 7 421-433. (doi:10.1016/j.cmet. 2008.04.005)

Holland WL, Miller RA, Wang ZV, Sun K, Barth BM, Bui HH, Davis KE, Bikman BT, Halberg N, Rutkowski JM et al. 2011 Receptor-mediated activation of ceramidase activity initiates the pleiotropic actions of adiponectin. Nature Medicine 17 55-63. (doi:10.1038/nm.2277)

Hotamisligil GS 2003 Inflammatory pathways and insulin action. International Journal of Obesity and Related Metabolic Disorders 27(Suppl 3) S53-S55. (doi:10.1038/sj.ijo.0802502)

Hotamisligil GS, Shargill NS \& Spiegelman BM 1993 Adipose expression of tumor necrosis factor- $\alpha$ : direct role in obesity-linked insulin resistance. Science 259 87-91. (doi:10.1126/science.7678183)

Hotamisligil GS, Arner P, Caro JF, Atkinson RL \& Spiegelman BM 1995 Increased adipose tissue expression of tumor necrosis factor- $\alpha$ in human obesity and insulin resistance. Journal of Clinical Investigation 95 2409-2415. (doi:10.1172/JCI117936)

Hotta K, Funahashi T, Arita Y, Takahashi M, Matsuda M, Okamoto Y, Iwahashi H, Kuriyama H, Ouchi N, Maeda K et al. 2000 Plasma concentrations of a novel, adipose-specific protein, adiponectin, in type 2 diabetic patients. Arteriosclerosis, Thrombosis, and Vascular Biology 20 1595-1599. (doi:10.1161/01.ATV.20.6.1595)

Hui JM, Hodge A, Farrell GC, Kench JG, Kriketos A \& George J 2004 Beyond insulin resistance in NASH: TNF- $\alpha$ or adiponectin? Hepatology 40 46-54. (doi:10.1002/hep.20280)

Itani SI, Ruderman NB, Schmieder F \& Boden G 2002 Lipid-induced insulin resistance in human muscle is associated with changes in diacylglycerol, protein kinase C, and ІкB- $\alpha$. Diabetes $512005-2011$ (doi:10.2337/diabetes.51.7.2005)

Jornayvaz FR \& Shulman GI 2012 Diacylglycerol activation of protein kinase $C \varepsilon$ and hepatic insulin resistance. Cell Metabolism 15 574-584. (doi:10.1016/j.cmet.2012.03.005)

Jornayvaz FR, Jurczak MJ, Lee HY, Birkenfeld AL, Frederick DW, Zhang D, Zhang XM, Samuel VT \& Shulman GI 2010 A high-fat, ketogenic diet causes hepatic insulin resistance in mice, despite increasing energy expenditure and preventing weight gain. American Journal of Physiology. Endocrinology and Metabolism 299 E808-E815. (doi:10.1152/ajpendo. 00361.2010)

Jornayvaz FR, Birkenfeld AL, Jurczak MJ, Kanda S, Guigni BA, Jiang DC, Zhang D, Lee HY, Samuel VT \& Shulman GI 2011 Hepatic insulin resistance in mice with hepatic overexpression of diacylglycerol acyltransferase 2. PNAS $\mathbf{1 0 8}$ 5748-5752. (doi:10.1073/pnas. 1103451108)

Jornayvaz FR, Lee HY, Jurczak MJ, Alves TC, Guebre-Egziabher F, Guigni BA, Zhang D, Samuel VT, Silva JE \& Shulman GI 2012 Thyroid hormone receptor- $\alpha$ gene knockout mice are protected from diet-induced hepatic insulin resistance. Endocrinology 153 583-591. (doi:10.1210/en.20111793)

Jung SH, Park HS, Kim KS, Choi WH, Ahn CW, Kim BT, Kim SM, Lee SY, Ahn SM, Kim YK et al. 2008 Effect of weight loss on some serum cytokines in human obesity: increase in IL-10 after weight loss. Journal of Nutritional Biochemistry 19 371-375. (doi:10.1016/j.jnutbio. 2007.05.007)

Jurczak MJ, Lee AH, Jornayvaz FR, Lee HY, Birkenfeld AL, Guigni BA, Kahn M, Samuel VT, Glimcher LH \& Shulman GI 2012 Dissociation of inositol-requiring enzyme (IRE1 $\alpha$ )-mediated c-Jun N-terminal kinase activation from hepatic insulin resistance in conditional X-boxbinding protein-1 (XBP1) knock-out mice. Journal of Biological Chemistry 287 2558-2567. (doi:10.1074/jbc.M111.316760)

Kern PA, Di Gregorio GB, Lu T, Rassouli N \& Ranganathan G 2003 Adiponectin expression from human adipose tissue: relation to obesity, insulin resistance, and tumor necrosis factor- $\alpha$ expression. Diabetes $\mathbf{5 2}$ 1779-1785. (doi:10.2337/diabetes.52.7.1779)

Kim JK, Fillmore JJ, Chen Y, Yu C, Moore IK, Pypaert M, Lutz EP, Kako Y, Velez-Carrasco W, Goldberg IJ et al. 2001 Tissue-specific overexpression of lipoprotein lipase causes tissue-specific insulin resistance. PNAS 98 7522-7527. (doi:10.1073/pnas.121164498)

Kishimoto T 2010 IL-6: from its discovery to clinical applications. International Immunology 22 347-352. (doi:10.1093/intimm/dxq030)

Kotronen A, Juurinen L, Tiikkainen M, Vehkavaara S \& Yki-Jarvinen H 2008 Increased liver fat, impaired insulin clearance, and hepatic and adipose tissue insulin resistance in type 2 diabetes. Gastroenterology 135 122-130. (doi:10.1053/j.gastro.2008.03.021)

Kumada M, Kihara S, Ouchi N, Kobayashi H, Okamoto Y, Ohashi K, Maeda K, Nagaretani H, Kishida K, Maeda N et al. 2004 Adiponectin specifically increased tissue inhibitor of metalloproteinase-1 through interleukin-10 expression in human macrophages. Circulation 109 2046-2049. (doi:10.1161/01.CIR.0000127953.98131.ED)

Lang CH, Dobrescu C \& Bagby GJ 1992 Tumor necrosis factor impairs insulin action on peripheral glucose disposal and hepatic glucose output. Endocrinology 130 43-52. (doi:10.1210/en.130.1.43)

Laplante M \& Sabatini D 2010 mTORC1 activates SREBP-1c and uncouples lipogenesis from gluconeogenesis. PNAS 107 3281-3282 (erratum: vol 107, pp 7617). (doi:10.1073/pnas.1000323107)

Lee YM, Sutedja DS, Wai CT, Dan YY, Aung MO, Zhou L, Cheng CL, Wee A \& Lim SG 2008 A randomized controlled pilot study of Pentoxifylline in patients with non-alcoholic steatohepatitis (NASH). Hepatology International 2 196-201. (doi:10.1007/s12072-008-9058-1)

Lee HY, Birkenfeld AL, Jornayvaz FR, Jurczak MJ, Kanda S, Popov V, Frederick DW, Zhang D, Guigni B, Bharadwaj KG et al. 2011 Apolipoprotein CIII overexpressing mice are predisposed to diet-induced hepatic steatosis and hepatic insulin resistance. Hepatology 54 1650-1660. (doi:10.1002/hep.24571) 
Le Moine O, Marchant A, Durand F, Ickx B, Pradier O, Belghiti J, Abramowicz D, Gelin M, Goldman M \& Deviere J 1994 Systemic release of interleukin-10 during orthotopic liver transplantation. Hepatology 20 889-892. (doi:10.1002/hep.1840200417)

Lesmana CR, Hasan I, Budihusodo U, Gani RA, Krisnuhoni E, Akbar N \& Lesmana LA 2009 Diagnostic value of a group of biochemical markers of liver fibrosis in patients with non-alcoholic steatohepatitis. Journal of Digestive Diseases 10 201-206. (doi:10.1111/j.1751-2980.2009.00386.x)

Lucero D, Zago V, Lopez GI, Graffigna M, Fainboim H, Miksztowicz V, Merono T, Belli S, Levalle O, Wikinski R et al. 2011 Pro-inflammatory and atherogenic circulating factors in non-alcoholic fatty liver disease associated to metabolic syndrome. Clinica Chimica Acta 412 143-147. (doi:10.1016/j.cca.2010.09.025)

Lumeng CN \& Saltiel AR 2011 Inflammatory links between obesity and metabolic disease. Journal of Clinical Investigation 121 2111-2117. (doi:10.1172/JCI57132)

Marchesini G, Brizi M, Bianchi G, Tomassetti S, Bugianesi E, Lenzi M, McCullough AJ, Natale S, Forlani G \& Melchionda N 2001 Nonalcoholic fatty liver disease: a feature of the metabolic syndrome. Diabetes 50 1844-1850. (doi:10.2337/diabetes.50.8.1844)

Marra F \& Bertolani C 2009 Adipokines in liver diseases. Hepatology 50 957-969. (doi:10.1002/hep.23046)

Meyer SG \& de Groot H 2003 Cycloserine and threo-dihydrosphingosine inhibit TNF- $\alpha$-induced cytotoxicity: evidence for the importance of de novo ceramide synthesis in TNF- $\alpha$ signaling. Biochimica et Biophysica Acta 1643 1-4. (doi:10.1016/j.bbamcr.2003.10.002)

Monetti M, Levin MC, Watt MJ, Sajan MP, Marmor S, Hubbard BK, Stevens RD, Bain JR, Newgard CB, Farese RV Sr et al. 2007 Dissociation of hepatic steatosis and insulin resistance in mice overexpressing DGAT in the liver. Cell Metabolism 6 69-78. (doi:10.1016/j.cmet.2007.05.005)

Moschen AR, Wieser V \& Tilg H 2012 Adiponectin: key player in the adipose tissue-liver crosstalk. Current Medicinal Chemistry 19 5467-5473. (doi:10.2174/092986712803833254)

Musso G, Cassader M, Rosina F \& Gambino R 2012 Impact of current treatments on liver disease, glucose metabolism and cardiovascular risk in non-alcoholic fatty liver disease (NAFLD): a systematic review and meta-analysis of randomised trials. Diabetologia 55 885-904. (doi:10.1007/s00125-011-2446-4)

Nadler ST, Stoehr JP, Rabaglia ME, Schueler KL, Birnbaum MJ \& Attie AD 2001 Normal Akt/PKB with reduced PI3K activation in insulin-resistant mice. American Journal of Physiology. Endocrinology and Metabolism 281 E1249-E1254.

Odegaard JI \& Chawla A 2013 Pleiotropic actions of insulin resistance and inflammation in metabolic homeostasis. Science 339 172-177. (doi:10.1126/science.1230721)

Ofei F, Hurel S, Newkirk J, Sopwith M \& Taylor R 1996 Effects of an engineered human anti-TNF- $\alpha$ antibody (CDP571) on insulin sensitivity and glycemic control in patients with NIDDM. Diabetes 45 881-885. (doi:10.2337/diabetes.45.7.881)

Park TS, Hu Y, Noh HL, Drosatos K, Okajima K, Buchanan J, Tuinei J, Homma S, Jiang XC, Abel ED et al. 2008 Ceramide is a cardiotoxin in lipotoxic cardiomyopathy. Journal of Lipid Research 49 2101-2112. (doi:10.1194/jlr.M800147-JLR200)

Petersen KF \& Shulman GI 2006 Etiology of insulin resistance. American Journal of Medicine 119 S10-S16. (doi:10.1016/j.amjmed.2006.01.009)

Petersen KF, Dufour S, Befroy D, Lehrke M, Hendler RE \& Shulman GI 2005 Reversal of nonalcoholic hepatic steatosis, hepatic insulin resistance, and hyperglycemia by moderate weight reduction in patients with type 2 diabetes. Diabetes 54 603-608. (doi:10.2337/diabetes.54.3.603)

Ratziu V, Bellentani S, Cortez-Pinto H, Day C \& Marchesini G 2010 A position statement on NAFLD/NASH based on the EASL 2009 special conference. Journal of Hepatology 53 372-384. (doi:10.1016/j.jhep.2010. 04.008)

Rodriguez A, Duran A, Selloum M, Champy MF, Diez-Guerra FJ, Flores JM, Serrano M, Auwerx J, Diaz-Meco MT \& Moscat J 2006 Mature-onset obesity and insulin resistance in mice deficient in the signaling adapter p62. Cell Metabolism 3 211-222. (doi:10.1016/j.cmet.2006.01.011)

Samuel VT, Liu ZX, Qu X, Elder BD, Bilz S, Befroy D, Romanelli AJ \& Shulman GI 2004 Mechanism of hepatic insulin resistance in non-alcoholic fatty liver disease. Journal of Biological Chemistry 279 32345-32353. (doi:10.1074/jbc.M313478200)

Savage DB, Choi CS, Samuel VT, Liu ZX, Zhang D, Wang A, Zhang XM, Cline GW, Yu XX, Geisler JG et al. 2006 Reversal of diet-induced hepatic steatosis and hepatic insulin resistance by antisense oligonucleotide inhibitors of acetyl-CoA carboxylases 1 and 2. Journal of Clinical Investigation 116 817-824. (doi:10.1172/JCI27300)

Schenk S, Saberi M \& Olefsky JM 2008 Insulin sensitivity: modulation by nutrients and inflammation. Journal of Clinical Investigation 118 2992-3002. (doi:10.1172/JCI34260)

Shoelson SE, Lee J \& Goldfine AB 2006 Inflammation and insulin resistance. Journal of Clinical Investigation 116 1793-1801. (doi:10.1172/ JCI29069)

Stefan N, Kantartzis K, Machann J, Schick F, Thamer C, Rittig K, Balletshofer B, Machicao F, Fritsche A \& Haring HU 2008 Identification and characterization of metabolically benign obesity in humans. Archives of Internal Medicine 168 1609-1616. (doi:10.1001/archinte.168. 15.1609)

Summers SA 2006 Ceramides in insulin resistance and lipotoxicity. Progress in Lipid Research 45 42-72. (doi:10.1016/j.plipres.2005.11.002)

Svedberg J, Stromblad G, Wirth A, Smith U \& Bjorntorp P 1991 Fatty acids in the portal vein of the rat regulate hepatic insulin clearance. Journal of Clinical Investigation 88 2054-2058. (doi:10.1172/JCI115534)

Tanti JF \& Jager J 2009 Cellular mechanisms of insulin resistance: role of stress-regulated serine kinases and insulin receptor substrates (IRS) serine phosphorylation. Current Opinion in Pharmacology 9 753-762. (doi:10.1016/j.coph.2009.07.004)

Tarantino G \& Caputi A 2011 JNKs, insulin resistance and inflammation: a possible link between NAFLD and coronary artery disease. World Journal of Gastroenterology 173785-3794. (doi:10.3748/wjg.v17.i33.3785)

Tarantino G, Savastano S \& Colao A 2010 Hepatic steatosis, low-grade chronic inflammation and hormone/growth factor/adipokine imbalance. World Journal of Gastroenterology 16 4773-4783. (doi:10.3748/wjg. v16.i38.4773)

Tilg H 2010 The role of cytokines in non-alcoholic fatty liver disease. Digestive Diseases 28 179-185. (doi:10.1159/000282083)

Tilg H \& Diehl AM 2000 Cytokines in alcoholic and nonalcoholic steatohepatitis. New England Journal of Medicine 343 1467-1476. (doi:10.1056/NEJM200011163432007)

Ueki K, Kondo T \& Kahn CR 2004 Suppressor of cytokine signaling 1 (SOCS-1) and SOCS-3 cause insulin resistance through inhibition of tyrosine phosphorylation of insulin receptor substrate proteins by discrete mechanisms. Molecular and Cellular Biology 24 5434-5446. (doi:10.1128/MCB.24.12.5434-5446.2004)

Unger RH 2001 Maurice Derot Prize 2001. The liporegulator system and disease. Journées Annuelles de Diabétologie de l'Hôtel-Dieu 129-143.

Unger RH 2002 Lipotoxic diseases. Annual Review of Medicine 53 319-336. (doi:10.1146/annurev.med.53.082901.104057)

Uysal KT, Wiesbrock SM, Marino MW \& Hotamisligil GS 1997 Protection from obesity-induced insulin resistance in mice lacking TNF- $\alpha$ function. Nature 389 610-614. (doi:10.1038/39335)

Wallenius V, Wallenius K, Ahren B, Rudling M, Carlsten H, Dickson SL, Ohlsson C \& Jansson JO 2002 Interleukin-6-deficient mice develop mature-onset obesity. Nature Medicine 8 75-79. (doi:10.1038/ nm0102-75)

Weickert MO \& Pfeiffer AF 2006 Signalling mechanisms linking hepatic glucose and lipid metabolism. Diabetologia 49 1732-1741. (doi:10.1007/s00125-006-0295-3)

Wellen KE \& Hotamisligil GS 2005 Inflammation, stress, and diabetes. Journal of Clinical Investigation 115 1111-1119. (doi:10.1172/JCI25102)

Wieckowska A, Papouchado BG, Li Z, Lopez R, Zein NN \& Feldstein AE 2008 Increased hepatic and circulating interleukin-6 levels in human 
nonalcoholic steatohepatitis. American Journal of Gastroenterology 103 1372-1379. (doi:10.1111/j.1572-0241.2007.01774.x)

Wiesenthal SR, Sandhu H, McCall RH, Tchipashvili V, Yoshii H, Polonsky K, Shi ZQ, Lewis GF, Mari A \& Giacca A 1999 Free fatty acids impair hepatic insulin extraction in vivo. Diabetes $\mathbf{4 8}$ 766-774. (doi:10.2337/diabetes. 48.4.766)

Wolf AM, Wolf D, Rumpold H, Enrich B \& Tilg H 2004 Adiponectin induces the anti-inflammatory cytokines IL-10 and IL-1RA in human leukocytes. Biochemical and Biophysical Research Communications 323 630-635. (doi:10.1016/j.bbrc.2004.08.145)

Xu H, Uysal KT, Becherer JD, Arner P \& Hotamisligil GS 2002 Altered tumor necrosis factor- $\alpha$ (TNF- $\alpha$ ) processing in adipocytes and increased expression of transmembrane TNF- $\alpha$ in obesity. Diabetes 51 1876-1883. (doi:10.2337/diabetes.51.6.1876)

Yamaguchi K, Itoh Y, Yokomizo C, Nishimura T, Niimi T, Fujii H, Okanoue T \& Yoshikawa T 2010 Blockade of interleukin-6 signaling enhances hepatic steatosis but improves liver injury in methionine choline-deficient diet-fed mice. Laboratory Investigation 90 1169-1178. (doi:10.1038/labinvest.2010.75)

Yang WS, Lee WJ, Funahashi T, Tanaka S, Matsuzawa Y, Chao CL, Chen CL, Tai TY \& Chuang LM 2001 Weight reduction increases plasma levels of an adipose-derived anti-inflammatory protein, adiponectin. Journal of
Clinical Endocrinology and Metabolism 86 3815-3819. (doi:10.1210/jc. 86.8.3815)

Yecies JL, Zhang HH, Menon S, Liu SH, Yecies D, Lipovsky AI, Gorgun C, Kwiatkowski DJ, Hotamisligil GS, Lee CH et al. 2011 Akt stimulates hepatic SREBP1c and lipogenesis through parallel mTORC1dependent and independent pathways. Cell Metabolism 14 21-32. (doi:10.1016/j.cmet.2011.06.002)

Younossi ZM, Stepanova M, Afendy M, Fang Y, Younossi Y, Mir H \& Srishord M 2011 Changes in the prevalence of the most common causes of chronic liver diseases in the United States from 1988 to 2008. Clinical Gastroenterology and Hepatology 9 524-530.e1 (quiz e60). (doi:10.1016/j. cgh.2011.03.020)

Yu XX, Murray SF, Pandey SK, Booten SL, Bao D, Song XZ, Kelly S, Chen S, McKay R \& Monia BP 2005 Antisense oligonucleotide reduction of DGAT2 expression improves hepatic steatosis and hyperlipidemia in obese mice. Hepatology 42 362-371. (doi:10.1002/ hep.20783)

Zhou YJ, Li YY, Nie YQ, Yang H, Zhan Q, Huang J, Shi SL, Lai XB \& Huang HL 2010 Influence of polygenetic polymorphisms on the susceptibility to non-alcoholic fatty liver disease of Chinese people. Journal of Gastroenterology and Hepatology 25 772-777. (doi:10.1111/j. 1440-1746.2009.06144.x)

Received in final form 19 June 2013

Accepted 5 July 2013

Accepted Preprint published online 5 July 2013
C 2013 Society for Endocrinology Printed in Great Britain 